\title{
The Etiology of Female Breast Cancer
}

\author{
Colin Sharpe ${ }^{a, b}$ Jean-François Boivin ${ }^{a, b}$ \\ ${ }^{a}$ Centre for Clinical Epidemiology and Community Studies, Sir Mortimer B. Davis-Jewish \\ General Hospital, and bJoint Departments of Epidemiology and Biostatistics and of \\ Occupational Health, McGill University, Montréal, Québec, Canada
}

\section{Key Words}

Breast neoplasms · Etiology · Epidemiology

\begin{abstract}
Considerable knowledge has been acquired about the determinants of female breast cancer. A positive family history among firstdegree relatives is associated with an increased risk of breast cancer, as is a past history of benign proliferative breast disease. Risk increases with decreasing age at menarche, and with increasing age at first full term pregnancy and at menopause. Pregnancy is followed by a short-term increase in risk, followed by a long-term decrease. Risk increases with age. Evidence that environmental determinants are involved comes from the study of migrant populations: migrants assume the risk of breast cancer prevalent in their new environment, arguing against the hypothesis that risk is determined solely by genetic mechanisms. The best un-
\end{abstract}

\begin{tabular}{ll}
\hline KARGER & ( 2000 S. Karger AG, Basel \\
Fax +4161306 1234 & $1011-7571 / 00 / 0091-0001 \$ 17.50 / 0$ \\
$\begin{array}{l}\text { E-Mail karger@karger.ch } \\
\text { www.karger.com }\end{array}$ & $\begin{array}{l}\text { Accessible online at: } \\
\text { www.karger.com/journals/mpp }\end{array}$
\end{tabular}

derstood environmental determinant is ionizing radiation: it increases risk in a dosedependent fashion. While ecologic studies of diet supported the hypothesis that high fat intake increases risk, cohort and case-control studies have yielded conflicting evidence, casting doubt on this hypothesis. However, weight gain during adult life is associated with an increased risk. Some drugs increase risk, specifically exogenous oestrogens and ethanol. The anti-oestrogen tamoxifen reduces risk. Recent evidence shows that both passive and active exposure to tobacco smoke is associated with an increased risk of breast cancer. Some women may be more susceptible to the effects of tobacco smoke on a genetic basis. Undoubtedly, other environmental determinants of breast cancer will be discovered.

\footnotetext{
Copyright $\Subset 2000$ S. Karger AG, Basel
}

\begin{tabular}{l}
\hline Dr. C.R. Sharpe \\
Epidemiology and Biostatistics Unit, Institut Armand-Frappier \\
531, boulevard des Prairies, Laval, Québec, H7N 1B7 (Canada) \\
Tel. +1 450687 5010, ext. 4200, Fax +1 4506865599 \\
E-Mail Csharp@dsuper.net
\end{tabular} 


\section{Pathology of Female Breast Cancer}

Normal Anatomy and Development of the Breast

The breast is a modified sweat gland consisting of 6-10 major duct systems, which converge at the nipple [1]. The milk producing glandular structures are known as lobules. Ductules within each lobule converge forming single terminal ducts, which, in turn, converge successively forming lactiferous ducts and then lactiferous sinuses. At puberty the ducts lengthen, the lobules begin to develop, and the surrounding fibrous tissue and fat proliferate [2]. During the postovulatory phase of each menstrual cycle the epithelial cells lining the ducts and lobules proliferate and slough at menstruation. The breast fully matures after pregnancy. Before the first pregnancy it contains many undifferentiated cells. During the first half of pregnancy the epithelium of the terminal ducts proliferates and the ducts divide further. During the second half the ductal system grows and the lobules develop fully. After pregnancy and lactation the lobules regress and the ducts shrink.

\section{Tumours of the Breast}

Benign breast tumours arise from either the intralobular stroma or the glandular epithelium [1], whereas malignant tumours arise from either ductal or lobular structures. Proliferative benign breast disease has been associated with an increased risk of breast cancer, but it is unclear whether it is a precursor of cancer or just a sign of previous exposures which may later result in cancer [3]. Breast cancers are classified as either non-invasive (in situ) or invasive [2], depending on whether they invade the epithelial basement membrane. Non-invasive cancers account for $10 \%$ of all breast cancers and invasive the remainder (90\%). Invasive ductal carcinoma accounts for about $60 \%$ of all breast cancers, and invasive lobular carcinoma, which probably arises from the terminal ductules, for about $15 \%$. Less frequent types of invasive carcinoma include medullary, tubular, and mucinous carcinomas.

\section{Experimental Studies of Mammary \\ Carcinogenesis}

An animal model of breast cancer offers insights relevant to the pathogenesis of the human disease $[4,5]$. The administration of 7,12-dimethylbenz(a)anthracene (DMBA), a polycyclic aromatic hydrocarbon, to rats causes the development of hormone-dependent mammary carcinomas histologically similar to human breast cancers. The development of the rat mammary gland resembles that of the human breast. The intermediate cells' in the epithelium of the rat mammary gland proliferate in response to hormonal stimulation and are the target of carcinogens. They correspond to the 'chief cells' in the human breast and are considered to be the epithelial stem cells which give rise to cancer.

The timing of administration of DMBA during development determines the nature of the neoplasms that develop. Immature, undifferentiated epithelial cells which rapidly proliferate in response to oestrogens are the most susceptible to carcinogenesis by DMBA. With exposure to DMBA the terminal end buds, the dilated club-like ends of the terminal ducts of prepubertal animals, develop intraductal proliferations which become carcinomas. Alveolar buds, the more differentiated precursors of lobules, form only benign cysts and fibro-adenomas. Susceptibility decreases with increasing age and after pregnancy and lactation, as a result of the decrease in immature, undifferentiated structures. Studies of the role of dietary fat in DMBA mammary carcinogenesis suggest that it is caloric intake rather than dietary fat that promotes tumour growth $[6,7]$. 


\section{Descriptive Epidemiology of Female Breast Cancer}

The incidence of breast cancer rises with increasing age. When the age-specific incidence rate of breast cancer is plotted against age on a log-log scale, incidence increases linearly with age until about 50 years of age, the age of menopause, after which the rate of increase decreases ('Clemmesen's Hook', fig. 1) [8].

Breast cancer incidence rates are highest in North America and Northern Europe, intermediate in Southern Europe and Latin America, and lowest in Asia and Africa, varying more than tenfold [9]. Rates have been increasing in some areas; e.g., in Japan the agestandardized rate increased by about $114 \%$ from 1968-1972 to 1983-1987. Age-standardized incidence rates for Kuwaitis and non-Kuwaitis living in Kuwait were 34.8 and 32.8 cases/100,000/year, respectively, for the periods 1988-1989 and 1992-1993 combined [10], in the middle range of rates for other countries in Asia.

The shape of the age-specific incidence curve changes according to the overall incidence rates for the populations [11]. In Japan, for example, where the rate was low from 1959 to 1960 , the age-specific rates decreased after 50 years of age, whereas, during the same period, in Finland, where the rates were intermediate, the rates stayed roughly constant after 50 years of age, and in Connecticut, where the rates were high, they increased after 50 years of age (fig. 2). [11].

Bjarnason et al. [11] analysed incidence data in Iceland for the period 1911-1972. They showed that the shape of the age-specific incidence curves changed from that of Japan where the incidence was low (1911-1929) to that of Connecticut where the incidence was high (1950-1972) [11] (fig. 3). When their data were replotted according to birth cohorts

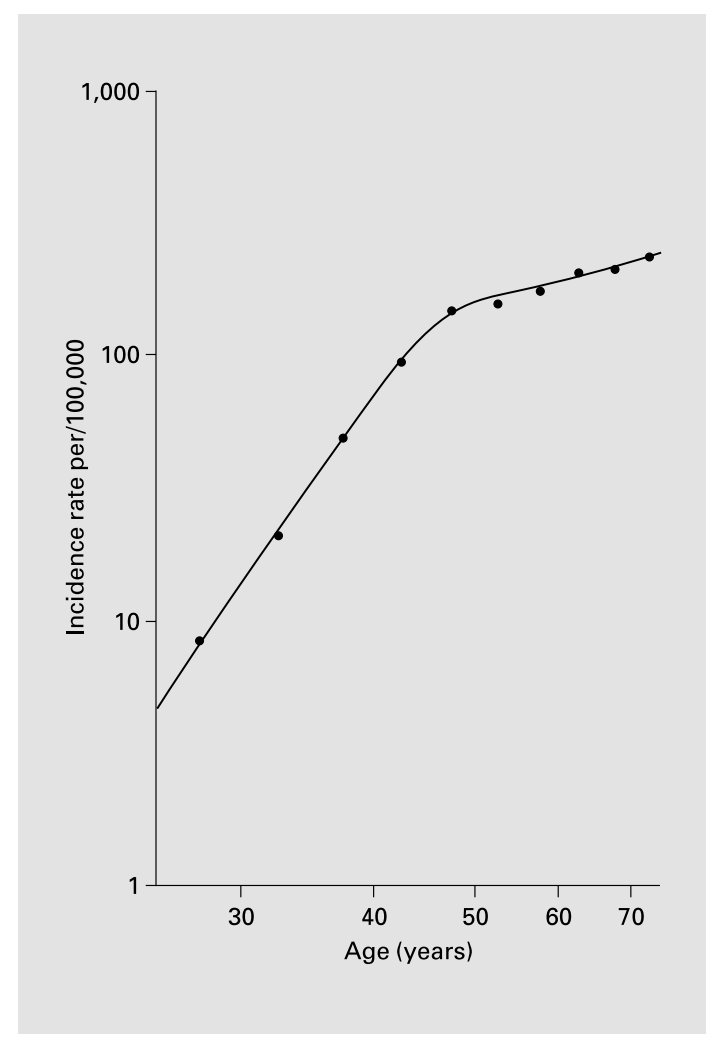

Fig. 1. Log-log plot of age-specific incidence rates for breast cancer (per 100,000) in US white women, 19691971. Reprinted from Pike et al. [8] with permission.

for women born into the ten decades from 1840 to 1939 , the age-specific incidence curves had roughly the same shapes, rather than the different shapes when plotted according to the time periods when the cancers were diagnosed. They interpreted these findings to mean that the changing shape of the age-specific incidence curves could be explained solely by the incidence increasing from one birth cohort to the next. Similar results were found in studies of data from Western nations and Japan $[12,13]$. The birth cohort effect was at a minimum for women born around 1900; incidence has been in- 
Fig. 2. Age-specific incidence of breast cancer in Connecticut (1960-1962), Finland (19591961), Japan, Miyagi Prefecture (1959-1960). Reprinted from Bjarnason et al. [11] with permission.

Fig. 3. Age-specific incidence of breast cancer in Iceland for the three time periods 1911-1929, 1930-1949, 1950-1972. Reprinted from Bjarnason et al. [11] with permission.
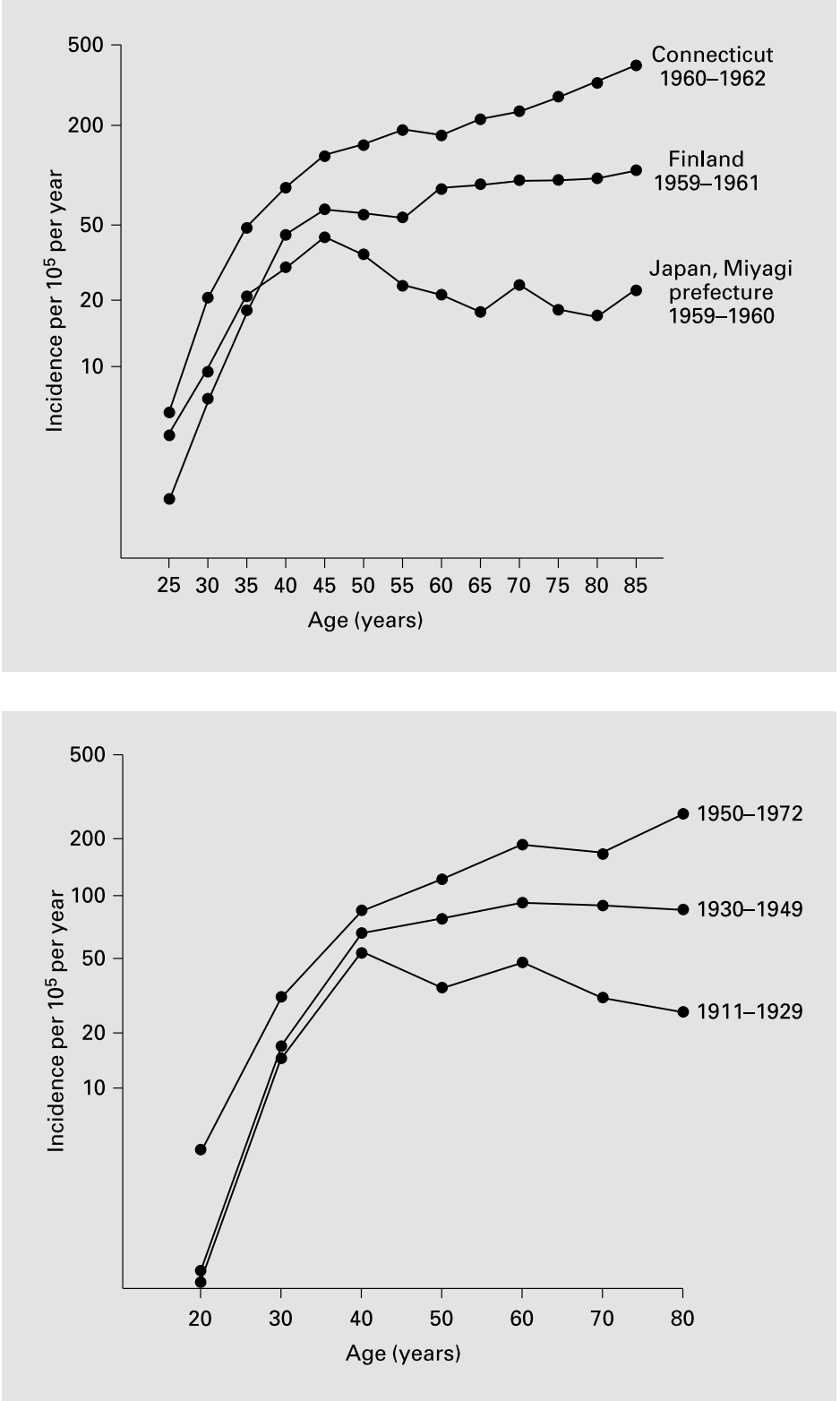

creasing since then, at different rates in different countries [13]. This could be related to secular changes in diagnostic methods and criteria. Bjarnason et al. [11] assumed that an exposure which has been increasing over time was causing the increasing incidence of breast cancer in Iceland. If this exposure could modify the risk of women who had already reached the age of appreciable incidence, then the age-specific incidence curves would vary 
with the increasing exposure over time. Since this did not occur (the age-specific incidence curves had similar shapes when plotted according to birth cohort), they concluded that the exposure produced the increase in risk before the age of appreciable incidence was reached, i.e. the exposure was confined to younger women or only the younger women were susceptible.

\section{Analytic Epidemiologic Studies of Breast Cancer}

The change in slope of the age-specific incidence rate of breast cancer as a function of age which occurs at the time of menopause has been interpreted as evidence for the involvement of ovarian hormones in the development of breast cancer, i.e., oestrogen and progesterone [8]. Although there is uncertainty about the effects of progesterone on the epithelial cells of the breast $[2,8,15]$, epidemiologic evidence shows the importance of the hormonal milieu and the timing of reproductive events during the lives of women.

\section{Prenatal Exposure to Oestrogens}

Increased concentrations of oestrogens in pregnancy might increase the probability of female foetuses eventually developing breast cancer [16-18]. Studies of infant breasts have revealed marked variation in the degree of development and differentiation, which may reflect variation in the hormonal milieu in utero between pregnant women.

\section{The Timing of Menarche}

In a cohort study carried out in Iceland, Tulinius et al. [19] found a trend to increasing risk of breast cancer with decreasing age at menarche, with a risk of 1.86 for women with menarche before 12 years of age relative to women with menarche at 16 years of age or later, after adjustment for year of birth. They concluded that the secular trend towards decreasing age at menarche could not account for the increasing incidence, since there were also secular trends towards decreasing age at first birth and a decreasing proportion of nulliparous women, risk factors with stronger effects than age at menarche, which would tend to decrease the incidence of breast cancer. They hypothesized that the increasing incidence must be due to an unidentified carcinogenic exposure.

Another estimate of the effect of age at menarche was derived from the analysis of the data from a large international hospitalbased case-control study carried out in seven cities in the late 1960s by MacMahon et al. [20, 21], the International Collaborative Study. In each centre, except Tokyo, the cases included almost all women hospitalized for a first diagnosis of breast cancer. Three controls per case were selected: they were the occupants of the beds closest to the beds of the cases who were free of breast cancer and were residents of the study area. Each 2-year delay in age at menarche was associated with an incidence rate ratio (RR) of 0.90 (95\% CI: 0.85-0.94).

Other determinants of age at menarche could be associated with the development of breast cancer. Menarche tends to occur sooner in girls with high energy-adjusted fat intakes: when comparing the highest quartile of fat intake to the lowest, the RR associated with accelerated menarche derived from a prospective study was 2.1 (95\% CI: 1.1-4.0) [22]. Menarche tended to occur later in girls with high levels of sports activity: the RR associated with delayed menarche was 0.3 (95\% CI: 0.1-0.5) when comparing the highest level of sports activity to the lowest. These effects may have been mediated by changes in body weight and body fat composition. Menarche tended to occur sooner in girls who were 
Fig. 4. Relative risk (relative to a risk of 1.0 for nulliparous women) of breast cancer according to age at first birth. Data for all centres combined. Reprinted from MacMahon et al. [21] with permission.

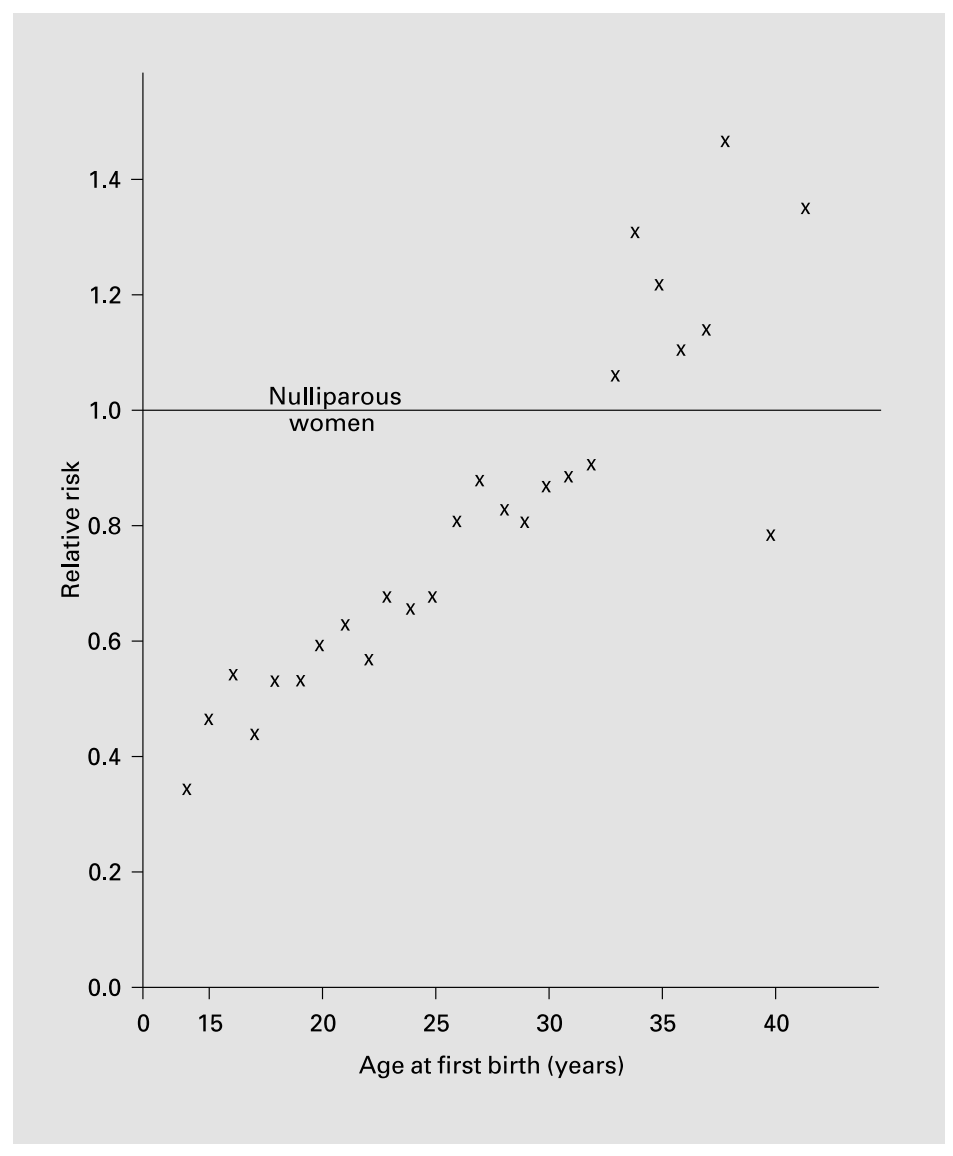

fatter: the RR was 4.0 (95\% CI: 2.1-7.5) when comparing the highest quartile of proportion of body fat to the lowest. Adipose tissue is a site of conversion of androgens to oestrogens, providing another source of oestrogens in addition to the ovaries, and it influences the metabolism of oestrogens to more or less potent forms.

\section{The Effects of Pregnancy and Its Timing}

The International Collaborative Study [21] showed that the risk of breast cancer increased linearly with the age at which a woman bore her first child up to about 30 years of age (fig. 4). Women whose first birth was de- layed until 35 years of age or more generally had higher risks than nulliparous women.

Restricting the analysis to uniparous women produced similar results, showing that the effect was unrelated to the protective effect of increasing parity. Using stratification, births after the first were shown to have little effect on risk. A reanalysis of this data with multiple logistic regression to control for age at all births, age at interview, parity, and centre produced a RR of 1.86 for an 18-year difference in age at first birth [23].

MacMahon et al. [21] reasoned that because the first pregnancy reduced risk for several decades afterwards, it must result in long- 
lasting changes that either reduce the exposure of the breast to carcinogens, such as oestrogens, or render the breast less sensitive. If young postpubertal women were intensely exposed to carcinogens, an early first pregnancy could reduce the duration of a high-risk period and limit tumour initiation. Since women over 35 years of age at the time of first delivery had higher risks of breast cancer than nulliparous women, they speculated that pregnancy could stimulate the growth of cells that had already undergone malignant transformation, whereas early first pregnancies could exert their protective effects before the occurrence of malignant transformation.

Several studies have examined how the risk of breast cancer changes over time after childbirth [24-27]. Pregnancy is followed by a short-term increase in risk, attributed to the tumour promoting effects of the high oestrogen levels during pregnancy on cells that had already undergone malignant transformation, followed by a long-term decrease in risk, attributed to the differentiating effect of pregnancy on normal mammary stem cells, which would reduce their risk of malignant transformation [25]. The degree of the reduction in risk depended on the age at first birth [26].

\section{The Effect of Incomplete Pregnancies}

How does an incomplete pregnancy affect the risk of breast cancer? It is important to distinguish between spontaneous and induced abortion, since the former could result from an insufficient increase in the hormones of pregnancy, whereas the latter ought to be accompanied by a normal increase [28]. It is also important to recognize that both spontaneous and induced abortions may be underreported: the former may go unrecognized, and the latter may be concealed, perhaps differentially depending on breast cancer status. A population-based case-control study of induced abortion and the risk of breast cancer carried out in The Netherlands showed such a bias in the reporting of induced abortions [29]. The association between induced abortion and breast cancer was much stronger in the predominantly Roman Catholic southeastern part of the country (adjusted RR $=14.6$; 95\% CI: 1.8-120.0) than in the western part where the incidence of induced abortion is twice as high (adjusted RR $=1.3 ; 95 \% \mathrm{CI}$ : $0.7-2.6$ ). The controls in the southeast may have underreported induced abortions, since they underreported the duration of their use of oral contraceptives by 6.3 months more than the controls in the west. The investigators concluded that an abortion registry is essential for studying its effects.

Melbye et al. [30] reported the results of a large cohort study based on data obtained by the Danish National Registry of Induced Abortions, which supplied data on all induced abortions from 1973 to 1992 . Information on parity and the vital status of all Danish women born between April 1, 1935 and March 31, 1978 was obtained from the Civil Registry System and cases of breast cancer were identified by the Danish Cancer Registry. Overall, there were 1.5 million women in the cohort: 280,965 women had 370,715 induced abortions and 10,246 developed breast cancer. The RR of breast cancer in women with a history of induced abortion was 1.00 (95\% CI: 0.94-1.06), after adjustment for age, parity, age at first delivery, and calendar period. However, adjustment for age at first birth may have attenuated the RR towards the null, since induced abortion will delay the age at first delivery for nulliparous women; i.e., age at first delivery may be an intermediate variable in the causal pathway between induced abortion and the development of breast cancer [31]. The data should be reanalysed. 


\section{The Effects of Lactation}

The International Collaborative Study tested the hypothesis that prolonged lactation reduces the risk of developing breast cancer [32], which was lower in countries where breast-feeding was customary and prolonged. The analysis was restricted to married women who had delivered at least 1 liveborn child. No protective effect of lactation was detected in this hospital-based case-control study [32].

Newcomb et al. [33] carried out a population-based case-control study in the USA restricted to parous women less than 75 years old to re-examine the issue. Among premenopausal women a history of lactation was associated with $\mathrm{RR}=0.78$ (95\% CI: 0.66-0.91), whereas no protective effect was noted among postmenopausal women $(\mathrm{RR}=0.97,95 \% \mathrm{CI}$ : 0.90-1.05), after adjustment for age at first delivery, parity, personal history of benign breast disease, family history of breast cancer, body mass index, and age at menarche. When the lifetime duration of lactation was categorized, among premenopausal women there was a significant trend $(\mathrm{p}<0.001)$ towards decreasing risk with increasing duration: $\mathrm{RR}=$ 0.72 (95\% CI: 0.51-0.99) for women who lactated for more than 24 months relative to women who never lactated. No such trend was observed among the postmenopausal women.

In addition, among the premenopausal women there was also a significant trend $(\mathrm{p}=$ $0.003)$ towards decreasing risk with decreasing age at first lactation $(\mathrm{RR}=0.54,95 \% \mathrm{CI}$ : 0.36-0.82) when compared to women who never lactated. No such trend was observed among the postmenopausal women. Among the premenopausal women, the effect was not influenced by adjustment for duration of lactation, nor did it vary according to the duration of lactation: the authors concluded that age at first lactation and duration of lactation contributed independently to the risk of breast cancer. They speculated that lactation could reduce the risk of breast cancer by interrupting ovulation, by modifying hormone secretion, or by resulting in excretion of carcinogens, but were unable to explain why the protective effect should be confined to premenopausal women.

To check if findings such as those just described could be related to recall bias, Michels et al. [34] carried out a cohort study using data collected in the Nurses' Health Study in the USA. No protective effect of lactation was found. Michels et al. [34] pointed out that most of the premenopausal cases in this study were close to menopause, which might explain why they did not demonstrate a protective effect. In addition, Michels et al. [34] controlled for more potential confounders than did Newcomb et al. [33]. It is conceivable that oral contraceptive use, alcohol intake, vitamin A intake, and physical activity, determinants of breast cancer accounted for by Michels et al. [34] but not by Newcomb et al. [33], could confound the relationship between lactation and breast cancer. American women who breast-feed may be more health-conscious than those who do not.

Kelsey et al. [35] and Kelsey and John [36] pointed out that studies carried out in developed countries may not show a protective effect of lactation because Western women generally lactate for shorter periods than women in developing contries and may be more likely to give their babies prepared formulas to supplement breast-feeding. In China, for example, 'relative risks of breast cancer of 0.5 or less have been reported for women who have lactated for 10 or more years, as compared with those who have lactated for less than 3 years' [36].

\section{The Effects of Menopause and Its Timing}

The effect of the timing of menopause on the risk of breast cancer was studied using data from the International Collaborative 
Study [20]. Among postmenopausal women the RR for the development of breast cancer was 1.17 (95\% CI: $1.11-1.22)$ for every 5-year increase in the age at menopause. At any given age, the RR of breast cancer was 1.26 (95\% CI: 1.10-1.43) for menstruating women versus postmenopausal women. 'The increased risk associated with early age at menarche and late age at menopause suggest that the longer the exposure to sex hormones during the reproductive years, the higher the risk of breast cancer' [35].

Recently, a nested case-control study has provided direct evidence that higher levels of circulating oestrogens in postmenopausal women are associated with a higher risk of breast cancer. Toniolo et al. [37] formed a cohort from 7,063 postmenopausal women aged 52 years or more who were attending a breast cancer screening clinic. After 52 years of follow-up (35,509 person-years), 130 cases of breast cancer were identified. Two controls per case were randomly selected from the cohort, matched on age at entry $( \pm 6$ months), date of enrolment ( \pm 3 months), and number and dates ( \pm 6 months) of subsequent blood donations, if any, at the screening clinic. Positive associations were found between serum concentrations $(\mathrm{pg} / \mathrm{ml})$ of biologically available oestradiol and the RR of breast cancer, i.e. for free or albumin-bound oestradiol but not for sex hormone binding globulin (SHBG)-bound oestradiol, which persisted after adjustment for the body mass index. When the highest quartiles were compared against the lowest, the RR for: (i) free oestradiol was 2.9 (95\% CI: 1.3-6.6); (ii) albumin-bound oestradiol was 2.2 (95\% CI: 1.04.8); (iii) SHBG-bound oestradiol was 1.3 (95\% CI: 0.6-2.6). For free oestradiol and albumin-bound oestradiol there were significant trends towards increasing risk with increasing concentration, but not for SHBGbound oestradiol.

Etiology of Female Breast Cancer

\section{Hormonal Contraceptives}

Many studies have examined the use of hormonal contraceptives in relation to the development of breast cancer, but questions remain about their effects [38]. The evidence from case-control studies to date has been limited by small sample sizes and the potential for selection and recall bias. The Collaborative Group on Hormonal Factors in Breast Cancer reanalysed individual data on 53,297 cases and 100,239 controls from 54 epidemiological studies of hormonal contraceptives carried out in 25 countries [39].

To ensure that women in one study were compared only with similar women in the same study the analyses were stratified simultaneously by study and by centre within study for multicentre studies, by age at diagnosis, parity, age at first birth, and by age when the risk of conception ceased forever. Current users of combined oral contraceptives were at slightly increased risk of developing breast cancer during the first 10-year period after cessation of use, but not afterwards: (1) current users, $\mathrm{RR}=1.24$ (95\% CI: $1.15-1.33)$; (ii) $1-4$ years after stopping, $\mathrm{RR}=1.16$ (95\% CI: 1.08 1.23); (iii) 5-9 years after stopping, $\mathrm{RR}=1.07$ (95\% CI: 1.02-1.13); (iv) $\geq 10$ years after stopping, $\mathrm{RR}=1.01$ (95\% CI: 0.96-1.05).

Once recency of use was accounted for, duration of use, age at first use, dose and type had little effect on risk. However, among current and recent users (last use $<5$ years ago) the RR was significantly elevated among those women with first use before age 20 years.

The breast cancers diagnosed in women who had used combined oral contraceptives tended to be less advanced clinically than those diagnosed in women who had never used them: for ever-users vs. never-users RR $=0.88(95 \%$ CI: 0.81-0.95) for spread beyond the breast. Was this an effect of oral contraceptives or due to surveillance bias?

Med Principles Pract 2000;9:1-24 
The authors concluded that the results were consistent with a tumour promoting effect, rather than an initiating effect: risk increased soon after exposure and returned to normal 10 years after stopping, and did not increase with duration of exposure. However, there was a flaw in the analysis of this study: the analyses were all adjusted for age at first birth. Since hormonal contraceptives are frequently used to delay the first birth, adjusting for age at first birth could attenuate the RR towards the null, it being an intermediate variable in the causal pathway between hormonal contraception and the development of breast cancer. It would only be appropriate to adjust for this variable in the situation where hormonal contraception was initiated after the first birth [31].

\section{Postmenopausal Hormone Replacement Therapy}

Assessment of the effects of postmenopausal hormone replacement therapy has been complicated by methodological issues similar to those discussed above for hormonal contraceptives, such as the potential for selection, recall, and surveillance bias [40]. Since the demonstrated increases in risk with the use of hormone replacement therapy have been small, statistical power tends to be an important issue. The exposure-disease relationship could be confounded by socioeconomic status [9], obesity [41], alcohol use [42], and the age at and type of menopause (natural vs. surgical), since both factors are related to the risk of breast cancer and to the probability of use of hormones [40].

Recently the Collaborative Group on Hormonal Factors in Breast Cancer reported the results of their study of the effects of hormonal replacement therapy which was based on the combined reanalysis of data from 51 studies of 52,705 women with breast cancer and 108,411 without breast cancer [43]. Current use of hormone replacement therapy was defined as use within 12 months of the index date. Age at menopause was defined as the age at which menstruation ceased. Women who started hormone replacement therapy before they ceased menstruating were classified as having an unknown age at menopause, as were women who underwent hysterectomy without bilateral oophorectomy, since it was unclear when cyclical ovarian function had ceased. The methods of analysis used in this study [43] were identical to those used in the Collaborative Group's earlier study of the effects of hormonal contraceptives [39].

Examination of the effects of the menopause on the risk of breast cancer was carried out by restricting the analysis to women who had never used hormone replacement therapy. For a given age and reproductive history the risk was less for postmenopausal women than for premenopausal women. The RR increased with increasing age at menopause and decreased thereafter.

Analysis of the effects of hormone replacement therapy excluded all premenopausal women as well as women with an unknown age at menopause, because time since menopause could not be estimated. It was essential to control for potential confounding by the time between menopause and the diagnosis of breast cancer. Thirty percent of the cases and $34 \%$ of the controls had used hormone replacement therapy. Among ever-users the median duration of use was 2 years. There was a small but significant increase in the RR of breast cancer associated with ever-use: $R R=$ $1.14, p=0.00001$. The RR increased with increasing duration of use $(p=0.003)$ and with time since first use $(p=0.03)$, although the RR was not increased for use that began less than 5 years ago. The RR was increased among current users $(1.21, p=0.00002)$, but not among past users. For current or recent users with a duration of use $\geq 5$ years the RR 
was $1.35(p=0.00001)$. The effect of increasing duration of use were examined among women whose last use was $<5$ years before diagnosis and among women whose last use was $\geq 5$ years before diagnosis. Among recent users (last use $<5$ years before diagnosis) there was a trend towards increasing RR with increasing duration of use: the risk increased by a factor of 1.023 for each year of use $(p=$ $0.0002)$. No such trend was seen among the women whose last use occurred $\geq 5$ years before diagnosis: $\mathrm{RR}=1.07$ (95\% CI: $0.97-$ 1.18).

The RR of breast cancer did not vary according to the type of hormone replacement therapy (oestrogen alone or in combination with a progestin), although only $12 \%$ of users were exposed to progestins. The breast cancers that developed among women who had used hormone replacement therapy were less likely to have spread to the axillary lymph nodes $(R R=0.82, p=0.02)$ or to distant sites $(\mathrm{RR}=0.54, \mathrm{p}=0.01)$ than to be localized to the breast $(\mathrm{RR}=1.00)$. Women with previously undiagnosed breast cancer may have been refused hormone replacement therapy when their physicians assessed their health. Hormone replacement therapy users may have been examined more frequently and thoroughly for signs of breast cancer. Alternatively, hormone replacement therapy may have influenced the behaviour of breast cancer.

The authors pointed out that their results pertain to hormone replacement therapy of relatively short duration that began around the onset of menopause [43]. As it is now being used for longer periods among older women, the topic should be re-examined in the future. Several important determinants were not considered in the analysis, the most important being daily dose. The potential for confounding by socioeconomic status and alcohol was not examined, nor was the potential

Etiology of Female Breast Cancer for effect modification by tobacco use, alcohol use, and previous oral contraceptive use.

\section{How Oestrogens May Influence the Risk of Breast Cancer}

Based on considerations of the mitogenic effects of oestrogens on the growth of breast tissue, Moolgavkar et al. [44] developed a model of carcinogenesis that predicts the shape of the curves relating incidence to age at diagnosis and the effects of the timing of reproductive events on risk. The model is illustrated in figure 5 [45].

Malignant cells arise from epithelial stem cells in the breast that undergo two irreversible events occurring with rates $\mu_{1}$ and $\mu_{2}$ [44, 45]. These events involve structural changes in DNA (mutations) that may be caused by exposure to environmental agents ('initiators' of carcinogenesis) and that are transmitted to subsequent generations of cells. Stem cells that differentiate, e.g. after the first full term pregnancy, or die are no longer at risk of malignant transformation. 'Promoters' of carcinogenesis such as oestrogens are agents which increase the population of stem cells that have already undergone one mutation ('intermediate' cells in fig. 5). Their replication, with rate $\alpha_{2}$, increases the probability that an intermediate cell will undergo a second mutation and become malignant. $\beta_{2}$ is the rate of differentiation and death of intermediate cells. The age-specific incidence rate per 100,000 women predicted by the model is $\mathrm{I}(\mathrm{t})$ $\mathrm{I} \times 10^{5}$, where

$$
I(t)=\mu_{1} \mu_{2} \int_{0}^{t} X(s) \exp \left\{\left(\alpha_{2}-\beta_{2}\right)(t-s)\right\} d s,
$$

and $\mathrm{X}(\mathrm{s})$ represents the number of normal susceptible cells at time (age) $\mathrm{s}$, described by a logistic function.

The model was applied to the data from six countries describing incidence as a function of age. The shape of the incidence curves was 


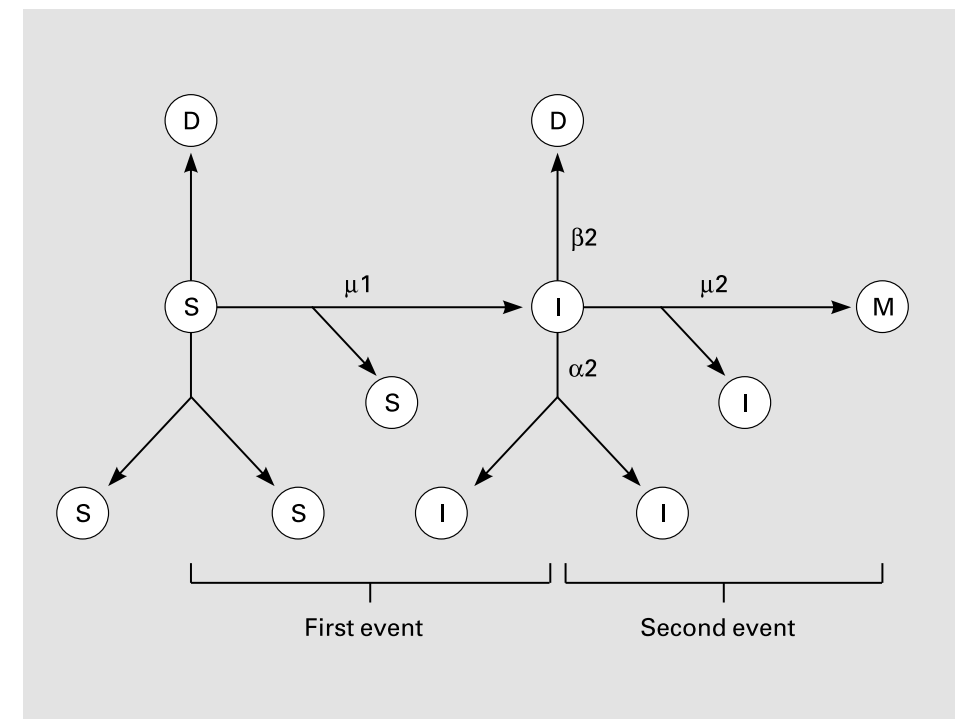

Fig. 5. Two-stage model for carcinogenesis. $S=$ Normal stem cell; $\mathrm{I}=$ intermediate (one-hit) cell; $\mathrm{D}=$ differentiated (or dead) cell; $\mathrm{M}=$ malignant cell; $\mu_{1}=$ rate at which first event occurs; $\mu_{2}=$ rate at which second event occurs; $\alpha_{2}=$ rate of division of intermediate cells; $\beta_{2}=$ rate of differentiation and death of intermediate cells. In a small time interval, a given stem cell (S) may divide with a certain probability to give rise to two daughter cells (S), or it may differentiate (or die) (D) and thus leave the pool of susceptible cells, or it may divide (with a small probability) into two cells, one of which is normal (S) and the other of which has suffered the first event to become an intermediate cell (I). The intermediate cell may in turn give rise to two intermediate daughters (I); die or differentiate (D); or give rise (with a small probability) to one intermediate cell (I) and one malignant cell (M). Reprinted from Moolgavkar [45] with permission. determined by the value of $\left(\alpha_{2}-\beta_{2}\right)$, the difference between the replication rate and the differentiation or death rate of the intermediate cells, which describes the growth of the breast as determined by hormonal stimulation. The overall incidence rates were determined by the product $\mu_{1} \mu_{2}$. The model fit the age-incidence curves for the six countries well when slightly different parameters for $\mathrm{X}(\mathrm{s})$ and values of $\mu_{1} \mu_{2}$ were used for each country, and when larger values of $\left(\alpha_{2}-\beta_{2}\right)$ were used for the premenopausal period than for the postmenopausal period. The model also described the increase in RR of breast cancer with increasing age at first birth that has been observed in epidemiologic studies [21, 23, 25,
26]. Thus, a model describing the growth characteristics of breast as determined by the promoting effects of oestrogens predicts that the timing of events in the reproductive lives of women plays a major role in determining the risk of breast cancer. Almost any hypothesis proposed to relate a putative determinant to the development of breast cancer will be examined in terms of how its effect could be mediated by its effects on oestrogen metabolism.

However, the distinction between initiation and promotion in the model may be an oversimplification. Ames and Gold [46] pointed out that the mitogenesis caused by promoters may actually result in increased 
mutagenesis. While we tend to think of mutagens as being exogenous agents, endogenous oxidants can cause DNA damage by the formation of adducts which is repaired, but not perfectly. A promoter may convert endogenous DNA damage into mutations by stimulating cell division, i.e. an adduct in the parent cell is transformed into a mutation in the daughter cells. A product of the metabolism of oestradiol may result in such effects. Oestradiol undergoes an initial oxidation of the 17\%hydroxy group yielding oestrone, which is then hydroxylated either at the C-2 or the 16- $\alpha$ position. The 2-hydroxyoestrogens have very little oestrogenic activity, whereas the $16 \alpha$-hydroxyoestrogens have oestrogenic activity comparable to the parent hormone, oestradiol, and have minimal affinity for the SHBG which ensures oestrogenic activity out of proportion to their circulating blood levels [47].

The extent of 16a-hydroxylation was shown to be significantly higher among breast cancer patients $(14.9 \%)$ than among healthy controls $(9.3 \%, \mathrm{p}<0.01)$ [47]. This difference preceded the development of breast cancer: the extent of 16a-hydroxylation was significantly higher among the high-risk women (14.1\%; daughters of breast cancer patients) than among the low-risk women $(11.0 \%, \mathrm{p}<$ 0.02) [48].

Telang et al. [49] demonstrated that $16 \alpha-$ hydroxyoestrone, which is produced by the 16a-hydroxylation of oestradiol, induces genotoxic damage and aberrant proliferation in mouse mammary epithelial cells by showing that the effects of 16 $\alpha$-hydroxyoestrone were comparable to the effects of DMBA with respect to indices of DNA repair (indicating DNA damage) and hyperproliferation measured in mouse mammary epithelial cell cultures, evidence that a metabolite of oestradiol produced by $16 \alpha$-hydroxylation is an initiator.

Etiology of Female Breast Cancer
Osborne et al. [50] compared the extent of $16 \alpha$-hydroxylation in normal breast tissue from 4 patients who underwent reduction mammoplasty and from 4 patients who underwent mastectomy for breast cancer. Terminal duct lobular units (TDLUs) were microdissected from surgical specimens and maintained as explant cultures. The extent of $16 \alpha$-hydroxylation in the TDLUs from the mastectomy patients was 4.56 times higher (95\% CI: 3.97-5.33) than in the TDLUs from the reduction mammoplasty patients.

Thus, the metabolism of oestradiol produces substances with oestrogenic activity that may function both as initiators and promoters. If the tendency to metabolize oestradiol via 16a-hydroxylation is inherited and persists, it could be an important determinant of breast cancer, as well as a useful risk indicator. However, the metabolism of oestradiol via either 2-hydroxylation or 16a-hydroxylation may be altered by environmental exposures. Davis et al. [51] suggested that substances that inhibit 2-hydroxylation or increase 16a-hydroxylation may increase risk, whereas substances that increase 2-hydroxylation or inhibit 16a-hydroxylation may decrease it. Caloric restriction increases 2-hydroxylation and inhibits 16a-hydroxylation, thereby possibly decreasing the risk of breast cancer. The dietary supplement, indole-3-carbinol, increases 2-hydroxylation and may reduce risk, whereas ethanol and linoleic acid increase 16a-hydroxylation and may increase it. The polycyclic aromatic hydrocarbons DMBA and benzo[a]pyrene inhibit 2-hydroxylation [51] and increase 16a-hydroxylation [52], possibly increasing risk. By influencing oestradiol metabolism these initiators may also act as promoters.

Diet as a Determinant of Breast Cancer

Variation in diet could be causally related to international variation in incidence rates of 
breast cancer, to increasing incidence rates over time in some countries, and to changes in incidence that occur with migration [41]. The most convincing evidence comes from studies of the effects of body size. A weak positive association exists between increasing height and the risk of breast cancer, for both premenopausal $(\mathrm{RR}=1.16$ for each $10-\mathrm{cm}$ increase in height, 95\% CI: 1.04-1.29) and postmenopausal $(\mathrm{RR}=1.15$ for each $10-\mathrm{cm}$ increase in height, 95\% CI: 1.08-1.22) breast cancer [53]. Attained height may be a proxy for energy intake during childhood: energy-deprived children do not reach their full potential height [41].

Among premenopausal women obesity was associated with a reduced risk of breast cancer $\left(\mathrm{RR}=0.98\right.$ for each $1 \mathrm{~kg} / \mathrm{m}^{2}, 95 \% \mathrm{CI}$ : 0.97-1.00), whereas among postmenopausal women the risk increased with obesity $(\mathrm{RR}=$ 1.03 for each $\left.1 \mathrm{~kg} / \mathrm{m}^{2}, 95 \% \mathrm{CI}: 1.02-1.04\right)$ and with weight gain since 18 years of age $(\mathrm{RR}=$ 1.07 for each $5 \mathrm{~kg}, 95 \% \mathrm{CI}: 1.05-1.09)$ and 35 years of age $(\mathrm{RR}=1.09$ for each $5 \mathrm{~kg}, 95 \% \mathrm{CI}$ : 1.06-1.12) [53]. Weight loss since these ages reduced the risk: $\mathrm{RR}=0.89$ (95\% CI: $0.76-$ $1.06)$ and $\mathrm{RR}=0.80$ (95\% CI: 0.69-0.94), respectively, for any weight loss $>1 \mathrm{~kg}$. Key and Pike [54] explained this differential effect of obesity: in premenopausal women it has little effect on total blood oestradiol levels but decreased progesterone production, reducing risk, whereas in postmenopausal women it increases total blood oestradiol and decreases SHBG, increasing free oestradiol and risk.

Which nutrients determine the risk of breast cancer? Ecologic studies showed that worldwide per capita fat consumption is linearly correlated with breast cancer mortality rates [55]. Hunter and Willett [41], however, pointed out that the per capita fat intakes in the ecologic studies were estimated from food disappearance calculations and may have seriously overestimated actual intake. The rela- tionship between dietary fat intake and the risk of breast cancer is likely to be seriously confounded by total energy intake. International variation in energy intake may explain much of the correlation between dietary fat intake and breast cancer rates. Finally, national per capita fat consumption is highly correlated with economic development, which tends to be associated with other strong risk factors for breast cancer, e.g. late age at first birth [41]. Ecologic studies cannot control such confounding.

Cohort studies 'provide solid evidence that no material relation exists between dietary fat intake and breast cancer incidence among women in developed countries during followup periods of up to 10 years' [41]. Because these studies have been criticized for lack of statistical power, misclassification of fat intake resulting in attenuated associations, and for the limited range of fat intake in the populations studied, Hunter et al. [56] carried out a pooled analysis of the data from seven excellent cohort studies and corrected their RR estimates for measurement error. When women in the highest quintile of energy-adjusted total fat intake were compared with women in the lowest quintile, the multivariate pooled RR was 1.05 (95\% CI: 0.94-1.16), indicating no effect. The types of fat ingested were not relevant. A major limitation of these studies and the pooled analysis was the short duration of follow-up: fat intake early in life could be relevant. Nevertheless, the authors concluded that 'it appears unlikely that a reduction in total fat consumption by middle-aged and older women will substantially reduce their risk of breast cancer' [56], although a reduction in total energy intake sufficient to produce weight loss might [53]. The hypothesis that energy restriction early in life and later may reduce the risk of breast cancer appears to be plausible.
Sharpe/Boivin 
Case-control studies of the relationship between fat intake and the risk of breast cancer have produced weak positive associations [41], which may not be valid due to the potential for selection and recall bias [57]. Since recall of past diet is so difficult, it is safe to conclude that prospective studies are more likely to provide valid results than retrospective studies.

High-fibre diets may reduce the risk of breast cancer by reducing the reabsorption of oestrogens excreted via the biliary system [41], but no protective effect of increasing total dietary fibre intake was found in the Nurses' Health Study after 8 years of followup [58]. The Nurses' Health Study, however, reported a protective effect of vitamin A [59] after both 4 and 8 years of follow-up. The multivariate RR for the highest quintile vs. the lowest for total vitamin A intake was 0.81 (95\% CI: $0.63-1.04)$ at 4 years and $0.84(95 \%$ CI: $0.71-0.98)$ at 8 years. The effect was nonlinear with a threshold: the risk of breast cancer was about $20 \%$ lower among the women in the highest four quintiles than among the women in the lowest quintile. A protective effect of vitamin A supplements was found only among the women in the lowest quintile of vitamin A intake from food. Vitamin A is a regulator of cell differentiation, and its precursors, the carotenoids, are anti-oxidants. No protective effects were found for the antioxidant vitamins $\mathrm{C}$ and $\mathrm{E}$. However, a protective effect of increasing the number of servings of vegetables per day was found.

\section{Physical Activity as a Determinant of \\ Breast Cancer}

Physical activity could reduce breast cancer risk by modifying the menstrual cycle and by reducing obesity [60,61]. It tends to delay menarche [22] and is also associated with decreased secretion of progesterone and reduced length of the luteal phase of the menstrual cycle, as well as anovulation, all of which may reduce risk. It has been hypothesized that physically active women, who tend to have less body fat than inactive women, might stop menstruating sooner, since obesity is associated with a late age at menopause [61].

The measurement of physical activity has been a major difficulty in evaluating its effects. All types of activity must be assessed to classify study subjects correctly, i.e. household, recreational, and occupational activity $[60,61]$, according to intensity, duration, and frequency. Furthermore, activity must be measured over the duration of subjects' lives to determine the most etiologically relevant periods. Various methods have been used: direct observation, physical activity records, survey instruments, and mechanical and electronic instruments. Unfortunately, the most practical methods which interfere least with subjects' activities tend to be the least valid and reliable [61].

Bernstein et al. [62] carried out a case-control study of physical exercise in relation to breast cancer diagnosed at age 40 years or younger in California. Selection bias may have been an issue in this study, which recruited 1 neighbourhood control per case, since a median of 32 dwellings were canvassed to select each control. They observed a reduction in risk associated with increasing physical activity that was greater among parous women $(\mathrm{RR}=0.28,95 \% \mathrm{CI}: 0.16-0.50, \mathrm{p}$ value for trend $<0.0001)$ than among nulliparous women $(\mathrm{RR}=0.73,95 \% \mathrm{CI}: 0.38-1.41, \mathrm{p}$ value for trend 0.43 ). While they adjusted for obesity and reproductive determinants in their analysis, Bernstein et al. [62] did not adjust for alcohol intake or diet. Confounding by alcohol intake and diet could account for some of the reduction in risk that was observed, if women who exercise regularly tend to consume less alcohol and more fruits and vegetables [63]. 
Thune et al. [64] carried out a large cohort study of physical activity and breast cancer in Norway, using data collected in two surveys of risk factors for cardiovascular disease. Two identical assessments of self-reported leisure activity in the year preceding each survey were made at an interval of 3-5 years and the results were combined: sedentary, moderate exercise, and regular exercise. Similar assessments were made of self-reported work activity: sedentary, walking, lifting, and heavy manual labour. After adjustment for age at entry into the cohort, body mass index, height, country of residence and number of children, significant trends towards decreasing RR of breast cancer were found for increasing levels of both leisure activity $(\mathrm{RR}=0.63$ for regular exercise vs. sedentary, $95 \%$ CI: $0.42-0.95$, p value for trend $=0.04$ ) and of work activity ( $R R=0.48$ for heavy manual labour vs. sedentary, $95 \%$ CI: $0.25-0.92$, $p$ value for trend $=$ $0.02)$.

When the data from both surveys were combined and the analysis was stratified according to body mass index, a significant trend towards decreasing RR of breast cancer was found for women in the lowest category of body mass index $\left(<22.8 \mathrm{~kg} / \mathrm{m}^{2}\right)$ with increasing leisure activity $(\mathrm{RR}=0.23$ for consistently active vs. consistently sedentary, 95\% CI: $0.09-0.60, \mathrm{p}$ value for trend $=0.002$ ). No such trends were found among the other two groups comprised of women with higher body mass indices, raising the possibility that a critical reduction of fat stores may be required to reduce risk [60]. The protective effect of leisure activity did not depend on menopausal status. Unfortunately, the potential for confounding by alcohol consumption, diet, use of oral contraceptives, hormone replacement therapy, income, and education in this study [64] was not assessed.

\section{Environmental Exposures as}

\section{Determinants of Breast Cancer}

Madigan et al. [65] estimated the proportion of breast cancer cases in the USA explained by well-established risk factors by measuring the population-attributable risks. They found that later age at first birth $(\geq 20$ years) and nulliparity accounted for $29.5 \%$ of US breast cancer cases (95\% CI: 5.6-53.3\%). A positive family history in a first-degree relative accounted for 9.1\% (95\% CI: 3.0-15.2\%). Family income in the upper two thirds of the USA population accounted for $18.9 \%$ of cases (95\% CI: -4.3 to $42.1 \%$ ). When these risk factors were considered in combination, having any of these factors accounted for $41 \%$ of cases (95\% CI: $2-80 \%)$ in the USA population. While it showed that a substantial proportion of breast cancer cases in the USA could be explained by the influence of these risk indicators, it also suggests that a substantial proportion remains unexplained. Other factors related to reproduction and lifestyle that may affect the internal hormonal milieu are likely to be relevant such as age at menarche, age at menopause, breast-feeding, energy intake and physical activity.

\section{The Effects of Migration on the Risk of Breast Cancer}

The observation that migrants tend to develop and die from breast cancer at rates closer to the country of adoption than the country of origin is the best evidence that environmental factors are mainly responsible for geographic variation in incidence rates. Multiple observational studies have been carried out of migration from countries of low incidence to the USA, a country of high incidence [66]. The rates of the descendants of immigrants are higher than those of their predecessors who migrated, which suggests that the exposures that increase risk exert their effects early in life. However, the rates in second-genera- 
tion Orientals were lower than in American white women, perhaps due to protective factors related to cultural characteristics that are maintained. Such putative protective factors may be specific for breast cancer, since rates of other cancers (e.g. colon, pancreas) approached American rates more rapidly over time. Variation in rates with migration is unlikely to be related to variation in reproductive patterns because the ratio of Japanese to American rates is almost as large for male breast cancer as for female breast cancer. Also, the observed incidence patterns are similar for single and married women.

Ziegler et al. [67] carried out a populationbased case-control study of migration patterns and the risk of breast cancer in Asian-American women, aged 20-55 years at diagnosis. Cases were all of Chinese, Japanese, or Filipino ethnicity. They attempted to obtain 2 controls per case by random digit dialling, frequency-matched for study area, ethnicity, and year of birth ( \pm 5 years), the only variables that were controlled for in their analyses. The study accrued 597 cases and 966 controls. Overall, this study found that the risk of breast cancer was 6 times higher among women born in the West with grandparents who were also born in the West compared to the risk among migrants from rural areas in the East whose grandparents were also born in the East.

Many of the factors discussed in previous sections that are determinants of endogenous oestrogen levels could vary with migration and increase risk. The Western environment may expose women to higher levels of substances that increase oestrogen metabolism via the 16a-hydroxylation pathway and thus function as xenoestrogens, such as organochlorine compounds, polycyclic aromatic hydrocarbons, and triazine herbicides [51]. Nested case-control studies using stored blood samples, collected years before diagnosis, to estimate such exposures are beginning to be published [68]. However, consistent patterns of results across studies are not yet emerging.

\section{The Effects of Ionizing Radiation on the Risk of Breast Cancer}

Ionizing radiation is the best understood environmental cause of breast cancer, despite the fact that it accounts for a small proportion of cases. Knowledge of its effects has been obtained from studies of survivors of the atomic bombing of Japan and of women exposed to repeated chest fluoroscopy and to radiotherapy [14]. The results of such studies of different populations have been very similar [69]. The RR of breast cancer is linearly dependent on radiation dose [70]. The effect of a given dose depends strongly on the age at which it is administered. For the survivors of the atomic bombing of Japan, the relationship between the excess RR (i.e. RR-1) for a 1sievert dose and age at the time of bombing was expressed as a negative exponential function: risk was greatest for the youngest group $(<10$ years at the time of bombing) and least for the oldest, with little or no excess risk for those older than 40 years at the time of bombing. Risk does not increase until at least 10 years after exposure [71]. Radiation dose has no effect on the timing of the diagnosis of breast cancer, nor does age at the time of exposure. Land et al. [72] studied these issues in a case-control study of breast cancer among survivors of the atomic bombing of Japan in which cases and controls were matched on age and city at the time of bombing and estimated radiation dose. Remarkably, among women exposed to radiation in childhood or adolescence, it was found that a first full term pregnancy at an early age following exposure appeared to provide protection against the effects of radiation [73]. The increase in breast epithelial cell differentiation produced by the first full term pregnancy $[4,21]$ may prevent 
further events from leading to malignant transformation.

\section{The Effects of Cigarette Smoking on the}

\section{Risk of Breast Cancer}

It was hypothesized that cigarette smokers would have a reduced risk of breast cancer because cigarette smoke has anti-oestrogenic effects [74]. Reduced urinary oestrogen levels are found in smokers during the luteal phase of the menstrual cycle and smokers tend to experience menopause earlier and to be thinner. However, it has also been hypothesized that smoking could increase the risk of breast cancer. Until recently, there has been little convincing evidence showing that smoking alters the risk of breast cancer [74].

However, Ambrosone et al. [75] carried out a case-control study of the effects of cigarette smoking on the risk of breast cancer in which they classified subjects according to their genetically determined capacity to detoxify carcinogenic aromatic amines in cigarette smoke. These compounds are detoxified and metabolically activated by various enzymes, including $\mathrm{N}$-acetyltransferase 2. Subjects were genotyped and classified as 'slow acetylators' if they carried two slow acetylator mutations and as 'rapid acetylators' if they carried zero or one slow acetylator mutation. Neither smoking nor acetylator phenotype was associated with an increased risk of breast cancer among premenopausal or postmenopausal women. However, among the postmenopausal women who were slow acetylators, significant trends $(\mathrm{p}<0.01)$ towards increasing risk of breast cancer were found for increasing number of cigarettes smoked per day 2 years and 20 years before diagnosis and for increasing number of pack-years. The RR for breast cancer associated with smoking $>20$ cigarettes/day 20 years before diagnosis was 3.9 (95\% CI: 1.4-10.8). No such trends were found among the postmenopausal rapid ace- tylators, nor among the premenopausal slow or rapid acetylators.

Ambrosone et al. [75] carried out a case series analysis for the postmenopausal cases and estimated the risk ratio of breast cancer for slow compared to rapid acetylators. The risk produced by smoking $>20$ cigarettes/day 20 years before diagnosis was 6.6 times greater for slow than for rapid acetylators $(95 \% \mathrm{CI}$ : 1.7-25.4). The risk associated with starting smoking at or before 16 years of age was 4.5 times greater for slow than for rapid acetylators (95\% CI: 1.3-14.9). There was a significant trend towards an increasing RR with decreasing age at first smoking.

The prevalence of the slow N-acetyltransferase 2 phenotype varies with ethnic origin. Among the white postmenopausal women in this study [75] it was $57 \%$, whereas it is 10 $20 \%$ among Asians. Thus, ethnic variation in genotype in relation to exposure to aromatic amines could explain some of the geographic variation in breast cancer risk.

The importance of this study is that it clarified how a common environmental exposure could be causally related to the development of breast cancer. However, a recent attempt to replicate these results by Hunter et al. [76] using data derived from the Nurses' Health Study did not show an increased risk of breast cancer among slow acetylators. The differing results could be related to selection bias due to non-response: smaller proportions of smokers underwent genotyping than non-smokers [76].

The results of several recent studies that have examined the relationships between both passive and active smoking and the risk of breast cancer have consistently found statistically significant associations, particularly for premenopausal breast cancer [77-81]. Failure to consider passive smoking when classifying subjects according to their exposure status in previous studies [74] may have 
resulted in misclassification that obscured the true underlying associations. Women who never smoked themselves but who lived or worked with smokers should not have been considered as unexposed to cigarette smoke. The truly unexposed were those women who never smoked themselves and who never lived or worked with smokers. For example, a recent Canadian study showed that regular passive smoking among premenopausal women who were never active smokers was associated with an RR of 2.3 (95\% CI: 1.2-4.6) and dose-response trends [81]. An identical RR was also observed for premenopausal women who had ever actively smoked. Although passive smoking among postmenopausal women was not associated with a statistically significant increased risk, regular active smoking among them was $\left(\mathrm{RR}=1.5,95 \% \mathrm{CI}: 1.0_{-}\right.$ 2.3).

The Effects of Alcohol Consumption on the Risk of Breast Cancer

Many studies have shown positive associations between alcohol use and breast cancer risk [82]. Longnecker et al. [83] and Longnecker [84] published meta-analyses showing that RR increased as a linear function of daily alcohol consumption. For three drinks/day $\mathrm{RR}=1.38,95 \% \mathrm{CI}: 1.23-1.55$. Although considerable attention was paid to the quality of the included studies, the timing of alcohol consumption in relation to the date of diagnosis was not clearly specified. Several studies attempted to determine whether the timing of alcohol use was relevant [82]. In one, recent use appeared to be most important, whereas use before 30 years of age did not seem to be relevant [85]. Among recent non-users, however, alcohol use early in life was associated with an increased risk.

It is unlikely that the positive association between alcohol use and the risk of breast cancer can be explained by selection or recall bias, since it has been observed consistently in well-conducted cohort studies [82]. The effect of alcohol could be mediated by its effects on circulating oestrogen levels. Reichman et al. [86] randomly assigned 34 premenopausal women to two groups in a controlled-diet crossover study lasting for six consecutive menstrual cycles. The women consumed $30 \mathrm{~g}$ of alcohol per day during either the first three or the last three menstrual cycles. Significant increases in total oestrogen levels and amount of bioavailable oestrogens were found in association with alcohol consumption. Another experimental study showed that alcohol ingestion increased circulating oestradiol levels threefold in women taking oestrogen replacement therapy, whereas it had no such effect in women not using oestrogen replacement therapy [42]. An observational study of postmenopausal women in the Nurses' Health Study [87] demonstrated a weak but significant positive linear association between alcohol consumption and plasma oestrone levels (Spearman correlation coefficient $=0.17, \mathrm{p}=$ 0.02).

\section{The Genetics of Breast Cancer}

\section{The Effects of Family History}

The risk of breast cancer is increased among women who have relatives with the disease [88]. A positive family history may represent a shared genetic predisposition as well as the influence of shared environmental exposures [89]. A remarkable case-control study evaluating the relation between family history and the risk of breast cancer was carried out in Utah by linking the Utah Cancer Registry to the Utah Genealogy Database, which spans as many as seven generations [90]. Compared to a woman with no known female relative with breast cancer, the RR of breast cancer for a woman with: (i) a first- 
degree female relative with breast cancer was 2.45 (95\% CI: 1.77-3.42); (ii) a second-degree female relative with breast cancer was 1.82 (95\% CI: 1.39-2.24); (iii) a third-degree female relative with breast cancer was 1.35 (95\% CI: 1.07-1.64); (iv) a fourth-degree female relative with breast cancer was 1.06 (95\% CI: 0.88-1.24).

\section{Results of Genetic Analyses}

Segregation analyses of kindreds with familial breast cancer suggested the existence of an autosomal dominant inherited predisposition to breast cancer caused by a gene with low prevalence and high penetrance [88]. Genetic linkage analyses led to the localization of two genes related to the development of breast cancer: (i) BRCA1 on chromosome 17q21; (ii) $B R C A 2$ on chromosome $13 \mathrm{q} 12-13$. The prior probability of carrying an inherited mutation of BRCA1 increases with decreasing age at diagnosis. Among families with breast cancer linked to $B R C A 1$ the cumulative incidence is $51 \%$ at age 50 years and $85 \%$ at age 70 years [88].

The function of $B R C A 1$ and $B R C A 2$ may be to maintain the integrity of the genome [91]. Inactivation of $B R C A 1$ or $B R C A 2$ could lead to increased mutation rates in other genes. The p53 tumour suppressor gene is also involved in portecting the integrity of the genome [92]. In response to noxious stimuli, p53 either activates a system which halts the cell cycle clock to prevent cell division until abnormalities are corrected or triggers apoptosis (programmed cell death). Mutations of p53 have been found in about half of the families with the Li-Fraumeni syndrome, which is also inherited as an autosomal dominant trait [88]. It is estimated that the carriers of p53 mutations in these families have a risk of $50 \%$ of developing breast cancer by 50 years of age.
In contrast to the clusters of breast cancers seen in families caused by rare, highly penetrant dominant susceptibility genes, there are disorders caused by gene abnormalities that are more common but less penetrant. These disorders do not produce familial clusters because of their low penetrance, but could account for a substantial proportion of all breast cancers because they are common [88]. Female relatives of patients with ataxia-telangectasia who are heterozygous for the mutation have an RR of breast cancer of 3.9 [88]. Since an estimated $1 \%$ of the general population may be heterozygous for the disorder, it could account for $8 \%$ of breast cancer diagnosed before age 40 years, and $2 \%$ of all cases diagnosed between 40 and 60 years of age.

\section{Conclusions}

Our understanding of the causes of breast cancer suggests opportunities for prevention. Critical is the realization that carcinogenesis is a prolonged multifactorial process. Consequently, to prove with randomized clinical trials that preventive efforts are effective may be exceedingly difficult. However, some of the most obvious suggestions are likely to be effective at preventing other diseases and at promoting overall health as well.

Avoiding unnecessary exposure to known carcinogens such as ionizing radiation is likely to be readily accepted by the public. Acceptance of the need to avoid alcohol consumption and exposure to tobacco smoke depend heavily on cultural norms, which can be modified by legislation banning advertising and consumption in public. Discovering the identity of the carcinogens that are as yet unknown should be a high priority for research.

Avoiding obesity should be a high priority throughout life to prevent both breast cancer and cardiovascular disease. Promoting physi- 
cal exercise from childhood to old age should be an essential component of such preventive efforts. Mezzetti et al. [93] estimated that $33.0 \%$ (95\% CI: 19.9-46.1) of breast cancer cases in Italy could be attributed to the combined effects of inadequate dietary intake of $\beta$-carotene, low levels of physical activity, and excessive alcohol consumption, which suggests that simple changes in diet and increasing physical activity could have a major impact on the incidence of breast cancer.

Since delaying the birth of the first child is a determinant of breast cancer and since childbirth is being postponed by women in many countries, consideration should be given to encouraging women to bear their children earlier in life. However, such efforts may conflict with other priorities, such as education and career plans. Accordingly, some re- searchers are presently attempting to develop hormonal contraceptives that would simulate the maturational effects of pregnancy on the breast.

The risks of the hormonal contraceptives currently used and oestrogen replacement therapy should be carefully considered on an individual basis by both physicians and their patients.

The discovery of inherited mutations that predispose to the development of breast cancer will lead to programmes of screening, combined with genetic counselling and monitoring for early detection and treatment. Women with such mutations may benefit from the discovery that the anti-oestrogen tamoxifen reduces the incidence of breast cancer [94].

\section{References}

1 Cotran RS, Kumar V, Robbins SL: Pathologic Basis of Disease, ed 5. Philadelphia, Saunders, 1994, pp 1089-1109.

2 Sharkey FE, Allred DC, Valente PT: Breast; in Damjanov I, Linder $\mathrm{J}$ (eds): Anderson's Pathology, ed 10. St Louis, Mosby, 1996, chapter 70, pp 2354-2388.

3 Bodian CA: Benign breast diseases, carcinoma in situ, and breast cancer risk. Epidemiol Rev 1993;15:177187.

4 Russo J, Tay LK, Russo IH: Differentiation of the mammary gland and susceptibility to carcinogenesis. Breast Cancer Res Treat 1982;2:573.

5 Russo J, Russo IH: Biological and molecular bases of mammary carcinogenesis. Lab Invest 1987;57:112137.

6 Kritchevsky D, Weber MM, Klurfeld DM: Dietary fat versus caloric content in initiation and promotion of 7,12-dimthylbenz(a)anthraceneinduced mammary tumorigenesis in rats. Cancer Res 1984;44:31743177 .
7 Albanes D: Total calories, body weight, and tumor incidence in mice. Cancer Res 1987;47:19871992.

8 Pike MC, Spicer DV, Dahmoush L, Press MF: Estrogens, progestogens, normal breast cell proliferation, and breast cancer risk. Epidemiol Rev 1993;15:17-35.

9 Kelsey JL, Horn-Ross PL: Breast cancer: Magnitude of the problem and descriptive epidemiology. Epidemiol Rev 1993;15:7-16.

10 Parkin DM, Whelan SL, Ferlay J, Raymond L, Young J (eds): Cancer incidence in five continents. Lyon, International Agency for Research on Cancer, 1997, vol VII, p 858.

11 Bjarnason O, Day N, Snaedal G, Tulinius $\mathrm{H}$ : The effect of year of birth on the breast cancer age-incidence curve in Iceland. Int J Cancer 1974; 13:689-696.

12 Moolgavkar SH, Stevens RG, Lee JAH: Effect of age on incidence of breast cancer in females. J Natl Cancer Inst 1979;62:493-501.
13 Stevens RG, Moolgavkar SH, Lee JAH: Temporal trends in breast cancer. Am J Epidemiol 1982;115:759777.

14 John EM, Kelsey JL: Radiation and other environmental exposures and breast cancer. Epidemiol Rev 1993; 15:157-162.

15 Bernstein L, Ross RK: Endogenous hormones and breast cancer risk. Epidemiol Rev 1993;15:48-65.

16 Trichopoulos D: Hypothesis: Does breast cancer originate in utero? Lancet 1990;335:939-940.

17 Adami H-O, Persson I, Ekbom A, Wolk A, Pouten J, Trichopoulos D: The aetiology and pathogenesis of human breast cancer. Mutat Res 1995;333:29-35.

18 Ekbom A, Trichopoulos D, Adami $\mathrm{H}-\mathrm{O}$, Hsieh CC, Lan SJ: Evidence of prenatal influences on breast cancer risk. Lancet 1992;340:1015-1018.

19 Tulinius H, Day NE, Johannesson $\mathrm{G}$, Bjarnason O, Gonzales M: Reproductive factors and risk for breast cancer in Iceland. Int $\mathrm{J}$ Cancer 1978;21:724-730. 
20 Hsieh C, Trichopoulos D, Katsouyanni K, Yuasa S: Age at menarche, age at menopause, height and obesity as risk factors for breast cancer: Associations and interactions in an international case-control study. Int J Cancer 1990;46:796-800.

21 MacMahon B, Cole P, Lin TM, Lowe CR, Mirra AP, Ravnihar B, Salber EJ, Valaoras VG, Yuasa S: Age at first birth and breast cancer risk. Bull World Health Organ 1970; 43:209-221.

22 Merzenich $\mathrm{H}$, Boeing $\mathrm{H}$, Wahrendorf J: Dietary fat and sports activity as determinants for age at menarche. Am J Epidemiol 1993;138: 217-224

23 Trichopoulos D, Hsieh C, MacMahon B, Lin LH, Lowe CR, Mirra AP, Ravnihar B, Salber EJ, Valaoras VG, Yuasa S: Age at any birth and breast cancer risk. Int $\mathrm{J}$ Cancer 1983;31:701-704.

24 Hsieh C, Pavia M, Lambe M, Lan SJ, Colditz GA, Ekbom A, Adami HO, Trichopoulos D, Willett WC: Dual effect of parity on breast cancer risk. Eur J Cancer 1994;30A 969-973.

25 Lambe M, Hsieh C, Trichopoulos D, Ekbom A, Pavia M, Adami HO Transient increase in the risk of breast cancer after giving birth. $\mathrm{N}$ Engl J Med 1994;331:5-9.

26 Rosner B, Colditz GA, Willett WC Reproductive risk factors in a prospective study of breast cancer: The Nurses' Health Study. Am J Epidemiol 1994;139:819-835.

27 Pike MC, Krailo MD, Henderson BE, Casagrande JT, Hoel DG: 'Hormonal' risk factors, 'breast tissue age' and the age-incidence of breast cancer. Nature 1983;303:767-770.

28 Michels KB, Willett WC: Does induced or spontaneous abortion affect the risk of breast cancer? Epidemiology 1996;7:521-528.

29 Rookus MA, van Leeuwen FE: Induced abortion and risk for breast cancer: Reporting (recall) bias in a Dutch case-control study. J Natl Cancer Inst 1996;88:1759-1764.

30 Melbye M, Wohlfahrt J, Olsen JH, Frisch M, Westergaerd T, HelwegLarsen K, Andersen PK: Induced abortion and the risk of breast cancer. N Engl J Med 1997;336:81-85.
31 Sharpe C: Adjustment for age at first birth in etiologic studies of breast cancer involving exposures that may affect age at first birth. Epidemiology 1999;10:95.

32 MacMahon B, Lin TN, Lowe CR, Mirra AP, Ravnihar B, Salber EJ, Trichopoulos D, Valaoras VG, Yuasa S: Lactation and cancer of the breast: A summary of an international study. Bull World Health Organ 1979;42:185-194.

33 Newcomb PA, Storer BE, Longnecker MP, Mittendorf R, Greenberg ER, Clapp RW, Burke KP, Willett WC, MacMahon B: Lactation and a reduced risk of premenopausal breast cancer. N Engl J Med 1994; 330:81-87.

34 Michels KB, Willett WC, Rosner BA, Manson JE, Hunter DJ, Colditz GA, Hankinson SE, Speizer FE: Prospective assessment of breastfeeding and breast cancer incidence among 89,887 women. Lancet 1996; 347:431-436.

35 Kelsey JL, Gammon MD, John EM: Reproductive factors and breast cancer. Epidemiol Rev 1993;15:3647

36 Kelsey JL, John EM: Lactation and the risk of breast cancer. N Engl J Med 1994;330:136-137.

37 Toniolo PG, Levitz M, ZeleniuchJacquotte A, Banerjee S, Koenig KL Shore RE, Strax P, Pasternak BS: A prospective study of endogenous estrogens and breast cancer in postmenopausal women. J Natl Cancer Inst 1995;87:190-197.

38 Malone KE, Daling JR, Weiss NS Oral contraceptives in relation to breast cancer. Epidemiol Rev 1993; 15:80-97.

39 Collaborative Group on Hormonal Factors in Breast Cancer: Breast cancer and hormonal contraceptives: Collaborative reanalysis of individual data on 53,297 women with breast cancer and 100,239 women without breast cancer from 54 epidemiological studies. Lancet 1996;347:1713-1727.

40 Brinton LA, Schairer C: Estrogen replacement therapy and breast cancer risk. Epidemiol Rev 1993;15: 66-79.

41 Hunter DJ, Willett WC: Diet, body size, and breast cancer. Epidemiol Rev 1993;15:110-132.
42 Ginsburg ES, Mello NK, Mendelson JH, Barbieri RL, Teoh SK, Rothman M, Gao X, Sholar JW: Effects of alcohol ingestion on estrogens in postmenopausal women. JAMA 1996;276:1747-1751.

43 Collaborative Group on Hormonal Factors in Breast Cancer: Breast cancer and hormone replacement therapy: Collaborative reanalysis of data from 51 epidemiological studies of 52,705 women with breast cancer and 108,411 women without breast cancer. Lancet 1997;350: 1047-1059.

44 Moolgavkar SH, Day NE, Stevens RG: Two-stage model for carcinogenesis: Epidemiology of breast cancer in females. J Natl Cancer Inst 1980;65:559-569.

45 Moolgavkar SH: Carcinogenesis modeling: From molecular biology to epidemiology. Annu Rev Public Health 1986;7:151-169.

46 Ames BN, Gold LS: Too many rodent carcinogens: Mitogenesis increases mutagenesis. Science 1990; 249:970-971.

47 Schneider J, Kinne D, Fracchia A, Pierce V, Anderson KE, Bradlow HL, Fishman J: Abnormal oxidative metabolism of estradiol in women with breast cancer. Proc Natl Acad Sci USA 1982;79:3047-3051.

48 Bradlow HL, Hershkopf R, Martucci C, Fishman J: 16 $\alpha$-hydroxylation of estradiol: A possible risk marker for breast cancer. Ann NY Acad Sci 1989;464:138-151.

49 Telang NT, Suto A, Wong GY, Osborne MP, Bradlow HL: Induction by estrogen metabolite $16 \alpha$-hydroxyestrone of genotoxic damage and aberrant proliferation in mouse mammary epithelial cells. J Natl Cancer Inst 1992;84:634-638.

50 Osborne MP, Bradlow HL, Wong GYC, Telang NT: Upregulation of estradiol C16 $\alpha$-hydroxylation in human breast tissue: A potential biomarker of breast cancer risk. J Natl Cancer Inst 1993;85:1917-1920.

51 Davis DL, Bradlow HL, Wolff $M$, Woodruff T, Hoel DG, Anton-Culver H: Medical hypothesis: Xenoestrogens as preventable causes of breast cancer. Environ Health Perspect 1993;101:372-377. 
52 Fishman J, Osborne MP, Telang NT: The role of estrogen in mammary carcinogenesis. Ann NY Acad Sci 1995;768:91-100.

53 Trentham-Dietz A, Newcomb PA, Storer BE, Longnecker MP, Baron J, Greenberg ER, Willett WC: Body size and risk of breast cancer. Am J Epidemiol 1997;145:1011-1019.

54 Key TJA, Pike MC: The role of oestrogens and progestagens in the epidemiology and prevention of breast cancer. Eur J Cancer Clin Oncol 1988;24:29-43.

55 Schatzkin A, Greenwald P, Byar DP, Clifford CK: The dietary fatbreast cancer hypothesis is alive JAMA 1989;261:3284-3287.

56 Hunter DJ, Spiegelman D, Adami HO, Beeson L, van den Brandt PA, Folsom AR, Fraser GE, Goldbohm RA, Graham S: Cohort studies of fat intake and the risk of breast cancer: A pooled analysis. $\mathrm{N}$ Engl $\mathrm{J}$ Med 1996;334:356-361.

57 Giovannucci E, Stampfer MJ, Colditz GA, Manson JE, Rosner BA, Longnecker M, Speizer FE, Willett WC: A comparison of prospective and retrospective assessments of diet in the study of breast cancer. Am J Epidemiol 1993;137:502511.

58 Willett WC, Hunter DJ, Stampfer MJ, Colditz G, Manson JE, Spiegelman D, Rosner B, Hennekens CH, Speizer FE: Dietary fat and fiber in relation to risk of breast cancer: An 8-year follow-up. JAMA 1992;268: 2037-2044.

59 Hunter DJ, Manson JE, Colditz GA Stampfer MJ, Rosner B, Hennekens $\mathrm{CH}$, Speizer FE, Willett WC: A prospective study of the intake of vitamins $\mathrm{C}, \mathrm{E}$, and $\mathrm{A}$ and the risk of breast cancer. N Engl J Med 1993; 329:234-240.

60 Gammon MD, Britton JA, Teitelbaum SL: Does physical activity reduce the risk of breast cancer? A review of the epidemiologic literature. Menopause 1996;3:172-180.

61 Friedenreich CM, Rohan TE: A review of physical activity and breast cancer. Epidemiology 1995;6:311317.
62 Bernstein L, Henderson BE, Hanisch R, Sullivan-Halley J, Ross RK: Physical exercise and reduced risk of breast cancer in young women. J Natl Cancer Inst 1994;86:14031408.

63 McTiernan A: Exercise and breast cancer: Time to get moving? N Engl J Med 1997;336:1311-1312.

64 Thune I, Brenn T, Lund E, Gaard M: Physical activity and the risk of breast cancer. N Engl J Med 1997; 336:1269-1275.

65 Madigan MP, Ziegler RG, Benichou J, Byrne C, Hoover RN: Proportion of breast cancer cases in the United States explained by well-established risk factors. J Natl Cancer Inst 1995; 87:1681-1685.

66 Thomas DB: Epidemiologic and related studies of breast cancer etiology. Rev Cancer Epidemiol 1980;1: 153-217.

67 Ziegler RG, Hoover RN, Pike MC, Hildesheim A, Nomura AM, West DW, Wu-Williams AH, Kolonel LN, Horn-Ross PL, Rosenthal JF, Hyer MB: Migration patterns and breast cancer risk in Asian-American women. J Natl Cancer Inst 1993;85:1819-1827.

68 Wolff MS, Toniolo PG, Lee EW, Rivera M, Dubin N: Blood levels of organochlorine residues and risk of breast cancer. J Natl Cancer Inst 1993; 85:648-652.

69 Land CE, Boice JD, Shore RE, Norman JE, Tokunaga M: Breast cancer risk from low-zone exposures to ionizing radiation: Results of parallel analysis of three exposed populations of women. J Natl Cancer Inst 1980;65:353-376.

70 Land CE: Studies of cancer and radiation dose among atomic bomb survivors: The example of breast cancer. JAMA 1995;274:402-407.

71 Land CE: Temporal distributions of risk for radiation-induced cancers. $\mathrm{J}$ Chron Dis 1987;40(suppl 2):45S$57 \mathrm{~S}$.

72 Land CE, Hayakawa N, Machado SG, Yamada Y, Pike MC, Akiba S, Tokunaga M: A case-control interview study of breast cancer among Japanese A-bomb survivors. I. Main effects. Cancer Causes Control 1994:5:157-165.
73 Land CE, Hayakawa N, Machado SG, Yamada Y, Pike MC, Akiba S, Tokunaga M: A case-control interview study of breast cancer among Japanese A-bomb survivors. II. Interactions with radiation dose. Cancer Causes Control 1994;5:167176.

74 Palmer JR, Rosenberg L: Cigarette smoking and the risk of breast cancer. Epidemiol Rev 1993;15:145156.

75 Ambrosone CB, Freudenhaim JL, Graham S, Marshall JR, Vena JE, Brasure JR, Michalek AM, Laughlin $\mathrm{R}$, Nemoto $\mathrm{T}$, Gillenwater KA, Shields PG: Cigarette smoking, $\mathrm{N}$ acetyltransferase 2 genetic polymorphisms, and breast cancer risk. JAMA 1996;276:1494-1501.

76 Hunter DJ, Hankinson SE, Hough $\mathrm{H}$, Gertig DM, Garcia-Closas M, Spiegelman D, Manson JE, Colditz GA, Willett WC, Speizer FE, Kelsey $\mathrm{K}$ : A prospective study of NAT2 acetylation genotype, cigarette smoking, and risk of breast cancer. Carcinogenesis 1997; 18:2127-2132.

77 Sandler DP, Wilcox AJ, Everson RB: Cumulative effects of lifetime passive smoking on cancer risk. Lancet 1985;i:312-315.

78 Smith SJ, Deacon JM, Chilvers CE, UK National Case-Control Study Group: Alcohol, smoking, passive smoking and caffeine in relation to breast cancer risk in young women. Br J Cancer 1994;70:112-119.

79 Morabia A, Bernstein M, Héritier S, Khatchatrian N: Relation of breast cancer with passive and active exposure to tobacco smoke. Am J Epidemiol 1996;143:918-928.

80 Lash TL, Aschengrau A: Active and passive cigarette smoking and the occurrence of breast cancer. Am J Epidemiol 1999;149:5-12.

81 Johnson KC, Hu J, Mao Y, and The Canadian Cancer Registries Epidemiology Research Group: Passive and active smoking and breast cancer risk in Canada, 1994-1997. Cancer Causes Control 2000; in press.

82 Rosenberg L, Metzger LS, Palmer JR: Alcohol consumption and risk of breast cancer: A review of the epidemiologic evidence. Epidemiol Rev 1993;15:133-144. 
83 Longnecker MP, Berlin JA, Orzan MJ, Chalmers TC: A meta-analysis of alcohol consumption in relation to risk of breast cancer. JAMA 1988 ; 260:652-656.

84 Longnecker MP: Alcoholic beverage consumption in relation to risk of breast cancer: Meta-analysis and review. Cancer Causes Control 1994, 5:73-82.

85 Longnecker MP, Newcomb PA, Mittendorf R, Greenberg ER, Clapp RW, Bogdan GF, Baron J, Macmahon B, Willett WC: Risk of breast cancer in relation to lifetime alcohol consumption. J Natl Cancer Inst 1995;87:923-929.

86 Reichman ME, Judd JT, Longcope C, Schatzkin A, Clevidence BA, Nair PP, Campbell WS, Taylor RR: Effects of alcohol consumption on plasma and urinary hormone concentrations in premenopausal women. J Natl Cancer Inst 1993;85:722727.
87 Hankinson SE, Willett WC, Manson JE, Hunter DJ, Colditz GA, Stampfer MJ, Longcope C, Speizer FE: Alcohol, height, and adiposity in relation to estrogen and prolactin levels in postmenopausal women. J Natl Cancer Inst 1995;87:1297-1302.

88 Greene MH: Genetics of breast cancer. Mayo Clin Proc 1997;72:5465.

89 Khoury MJ, Beaty TH, Cohen BH: Fundamentals of Genetic Epidemiology. New York, Oxford University Press, 1993, pp 164-199.

90 Slattery ML, Kerber RA: A comprehensive evaluation of family history and breast cancer risk: The Utah Population Database. JAMA 1993; 270:1563-1568.

91 Kinzler KW, Vogelstein B: Gatekeepers and caretakers. Nature 1997;386:761-763.
92 Jacks T, Weinberg RA: Cell-cycle control and its watchman. Nature 1996;381:643-644.

93 Mezzetti M, La Vecchia C, Decarli A, Boyle P, Talamini R, Franceschi S: Population attributable risk for breast cancer: Diet, nutrition, and physical exercise. J Natl Cancer Inst 1998;90:389-394.

94 Fisher B, Costantino JP, Wickerham DL, Redmond CK, Kavanah M, Cronin WM, Vogel V, Robidoux A, Dimitrov N, Atkins J, Daly M, Wieand S, Tan-Chiu E, Ford L, Wolmark N, and other National Surgical Adjuvant Breast and Bowel Project Investigators: Tamoxifen for prevention of breast cancer: Report of the National Surgical Adjuvant Breast and Bowel Project P-1 study. J Natl Cancer Inst 1998;90:13711388. 